\title{
Phases of economic development: do initial endowments matter?
}

\author{
Manuel A. Gómez* \\ Universidad de A Coruña \\ Tiago N. Sequeira ${ }^{\dagger}$ \\ Universidade da Beira Interior and \\ INOVA, Nova School of Business and Economics
}

\begin{abstract}
Different industrializing experiences beginning on innovation or education could be explained not only by different structural parameters or policies but also by differences in factor endowments. In this paper, we consider an endogenous growth model with physical capital, human capital and R\&D. We show that the initial endowments can determine the sequence of the phases of development that the economy follows; in particular, whether innovation precedes education or viceversa.
\end{abstract}

Key-Words: Endogenous growth, Transitional Dynamics, Innovation, Education. JEL Classification: O31, O33, O41.

*Department of Applied Economics II, University of A Coruña, Campus de Elviña, 15071 A Coruña, Spain. Tel.:+34 981167000. Fax: +34 981 167070. E-mail: mago@udc.es.

${ }^{\dagger}$ Departamento de Gestão e Economia. Universidade da Beira Interior. Estrada do Sineiro. 6200-209 Covilhã. Portugal. Tel.: +351 275319700. Fax: +351 275329183. E-mail: sequeira@ubi.pt. 


\section{Introduction}

There is a broad consensus in the literature that physical capital accumulation, knowledge formation, and R\&D-based technological progress are the three main engines of growth. The relative importance of each of them characterizes the different phases of development that an economy passes through as it evolves. In a series of papers, Arnold (2000) and Funke and Strulik (2000) (AFS henceforth) and, subsequently, Sequeira (2011), Iacopetta (2011) and Gómez (2011a,b) devise a class of endogenous growth models that integrates physical capital, human capital and R\&D in a common framework. Funke and Strulik (2000) conjecture that an advanced economy passes through three stages of development. At the first stage the standard neoclassical model, physical capital is the only factor being accumulated; at the second stage - a knowledge economy in the Uzawa-Lucas framework, human capital is also being accumulated, and at the third stage - the fully industrialized economy, R\&D is actively being conducted as well. Simulation results presented by Funke and Strulik (2000) and Gómez (2005) exemplify this development sequence.

Most economic historians agree, however, that formal education has not played a significant role in the British Industrial Revolution (e.g., Mitch, 1993, Mokyr, 1990). Evidence reviewed by Galor (2005) and Galor and Moav (2006) shows that in the first phase of industrialization educational requirements in the production process were minimal, and education served religious, social, or national goals. It was not until the second phase of the Industrial Revolution that the increasing pace of technological progress ultimately brought about an industrial demand for human capital, because skills became necessary for production, which stimulated human capital formation. Accordingly, Iacopetta (2010) argues that an innovation-education sequence could agree better than an education-innovation transition with historical data, and shows that the AFS model can also generate a development scenario in which the transition dynamics is characterized by an innovative stage - without knowledge accumulation - followed by a fully industrialized phase. To this end, Iacopetta provides simulation results that exemplify an innovation-education sequence of development stages and, for a different set of parameter values, numerical simulations that exemplify an education-innovation transition.

The role of human capital in the industrialization process could nevertheless have been different across nations. In this respect, evidence on the Prussian Industrial Revolution recently provided by Becker et al. (2011) suggests that, unlike the British Industrial Revolution, basic education could have played a crucial role in the industrial catch-up of the technological follower countries because it is a key ingredient for the adoption of new technologies. This leads us back again to the plausibility of an education-innovation sequence of development phases as argued by Funke and Strulik (2000).

The numerical simulations made by Iacopetta (2010) show that the AFS model is actually able to generate transition dynamics in which innovation precedes education as well as the education-innovation sequence for different parameterizations and also different initial values. This is due to the fact that initial endowments are not kept constant across simulations. Hence, Iacopetta's results illustrate the flexibility of the AFS model to replicate alternative sequences of development phases for economies that differ in underlying preference and/or production parameters as well as in initial endowments. The main contribution of this paper 
is to show that differences in initial endowments alone are sufficient to generate different sequences of development stages.

Some recent and influential literature has focused on the importance of initial conditions linked with history and geography - and independent from structural production, preferences or policy parameters - in determining the subsequent development path (e.g. Acemoglu et al., 2001, Easterly and Levine, 2003, Galor, 2010). This literature views the evolution of the economy as predetermined by factors that cannot be influenced by policy. According to this, the relative factor endowments alone could determine whether it is more profitable to start investing in education or in $R \& D$, without the need to resorting to different preferences or production structures to explain it. Hence, we ask whether initial conditions alone can determine the stages of development that an economy passes through; i.e., whether innovation precedes education or vice versa. In this paper, we show that the extended AFS model can replicate a situation in which two identical economies, aside from their factor endowments, can follow different sequences of development phases. Alternatively said, we show that parameter differences are not really necessary to explain different sequences of development phases as previous works suggest.

For our analysis we consider the model proposed by Sequeira (2011), which incorporates spillovers in R\&D to the AFS model, as the simplest AFS model yields macroeconomic dynamics that is contrary to historical evidence. In fact, Gómez (2011b) examines the performance of the AFS model to describe the development process. He shows that previously reported simulations made by Funke and Strulik (2000), Gómez (2005) and Iacopetta (2010) feature three main problems, namely, the instability issue, too fast convergence, and unrealistic highly oscillatory dynamics. First, in the simulations made by Funke and Strulik (2000) and in three out of the four ones made by Iacopetta (2010), the steady state of the last development stage - the fully industrialized economy - is unstable, because the number of unstable roots exceeds the number of jump variables. Hence, it is not possible to make the system stable for arbitrary initial values of the predetermined variables. Second, (once corrected) in the remaining simulation made by Iacopetta (2010), convergence is too fast to represent in an adequate manner the observed historical data and, like the simulations made by Gómez (2005), they feature unrealistic highly oscillatory dynamics which are at odds with data. All these features have to do with the stable roots of the dynamic system that leads the economy. So, Gómez (2011b) performs a detailed sensitivity analysis of the stable roots of the fully industrialized economy which suggests that numerical simulations with the AFS model could hardly be reconciled with data. On the one hand, saddle-path stability is achieved for a relatively small set of parameter values and, in particular, instability results for realistic values of the markup. On the other hand, the two stable roots are much more likely to be complex conjugate, and even when the real part is low enough to accommodate a sufficiently long transition, the imaginary part is relatively high, so that the model features unrealistic highly oscillatory dynamics which is at odds with data.

The contribution of this article is to present realistic transitional dynamics that can match the innovation-human capital historical dynamics for the first and the second industrial revolution. It is shown that different realistic transitional dynamics for the first and the second industrial revolutions can be solely due to differences in initial endowments. This may be considered of major importance in the light of the discussion between the relevance of policies and/or of initial conditions. 
The remainder of this paper is organized as follows. Section 2 describes the model. Section 3 characterizes the different stages of development. Section 4 presents some simulation results to show that the model can generate realistic adjustment dynamics in which innovation precedes education or vice versa depending only on the initial endowments. Section 5 concludes.

\section{The model}

This section describes the endogenous growth model with physical capital, human capital and varieties introduced by Sequeira (2011), which incorporates spillovers in R\&D to the AFS model. In fact, the original AFS model was the one previously considered by Iacopetta (2010). Sequeira solves the model only for the last stage of development - the fully industrialized economy -, which is characterized by both knowledge formation and R\&D, as well as physical capital accumulation. However, given that we are interested in the stages of development that an economy can pass through, we will also solve for the cases in which there is not knowledge formation and/or innovation, following what first Funke and Strulik (2000) and then Iacopetta (2010) and Gómez (2011b) have also done.

Consider a closed economy inhabited by a constant population, normalized to one, of identical individuals who derive utility from consumption, $C$, according to

$$
\int_{0}^{\infty} \frac{C^{1-\theta}-1}{1-\theta} e^{-\rho t} d t, \quad \rho>0,
$$

where $\rho$ is the time-discount rate, and $\theta$ is the relative risk aversion coefficient. Individual's time, which is normalized to unity, can be devoted to production, $u_{P}$, education, $u_{E}$, or innovation, $u_{I}=1-u_{P}-u_{E}$. The accumulation of human capital, $H$, is a non-market activity, and follows the law

$$
\dot{H}=\xi u_{E} H, \quad \xi>0 .
$$

The budget constraint faced by the representative individual is

$$
\dot{A}=r A+w\left(1-u_{E}\right) H-C
$$

where $w$ is the wage rate per unit of employed human capital, and $r$ is the return per unit of aggregate wealth $A$. Let $g_{x}$ denote $x$ 's growth rate, $g_{x}=\dot{x} / x$. The individual maximizes her intertemporal utility (1), subject to the budget constraint (3) and the knowledge accumulation technology (2). The first order conditions yield

$$
g_{C}=(r-\rho) / \theta
$$

and

$$
r-g_{w}=\xi \quad \text { and } \quad u_{E}>0,
$$

in an equilibrium with education, or

$$
r-g_{w}>\xi \text { and } u_{E}=0 .
$$


Output, $Y$, is produced with a Cobb-Douglas technology

$$
Y=K^{\beta} D^{\eta}\left(u_{P} H\right)^{1-\beta-\eta}, \quad \beta>0, \quad \eta>0, \quad \beta+\eta<1,
$$

where $K$ is the physical capital stock, and $D$ is an index of intermediate goods, $D=$ $\left(\int_{0}^{n} x_{i}^{\alpha} d i\right)^{1 / \alpha}, 0<\alpha<1$, where $x_{i}$ is the amount used for each one of the $n$ intermediate goods. The parameter $\alpha$ governs the substitutability between varieties. The market for final goods is perfectly competitive and the price for final goods is normalized to one. Profit maximization delivers the factor demands

$$
\begin{aligned}
r & =\beta Y / K, \\
w & =(1-\beta-\eta) Y /\left(u_{P} H\right), \\
p_{i} & =\eta Y x_{i}^{\alpha-1} / D^{\alpha},
\end{aligned}
$$

where $p_{i}$ represents the price of intermediate $i$.

Invention of new intermediates is determined according to

$$
\dot{n}=\epsilon u_{I} H n^{\phi}, \quad \epsilon>0, \quad 0<\phi<1 .
$$

Each firm in the intermediate goods sector owns an infinitely-lived patent for selling its variety $x_{i}$, so there is monopolistic competition in the intermediate-goods sector. An intermediate good costs one unit of $Y$ to produce. Facing the price elasticity of demand for the intermediates $1 /(1-\alpha)$, firms maximize operating profits, $\pi_{i}=\left(p_{i}-1\right) x_{i}$, by charging a constant markup price $p_{i}=1 / \alpha$. Since both technology and demand are the same for all intermediates, the equilibrium is symmetric: $x_{i}=x, p_{i}=p$. Hence, the quantity of intermediates employed is $x n=\alpha \eta Y$, firms profits are

$$
\pi=(1-\alpha) \eta Y / n
$$

and $D=x n^{1 / \alpha}=n^{(1-\alpha) / \alpha} \alpha \eta Y$. Substituting this expression into (7) yields

$$
Y^{1-\eta}=(\alpha \eta)^{\eta} K^{\beta} n^{(1-\alpha) \eta / \alpha}\left(u_{P} H\right)^{1-\beta-\eta} .
$$

The value of an innovation $v$ is the present value of the stream of monopoly profits, $v(t)=$ $\int_{t}^{\infty} e^{-\bar{r}(\tau, t)} \pi(\tau) d \tau$, with $\bar{r}(\tau, t)=\int_{t}^{\tau} r(s) d s$. Differentiating this expression with respect to time yields the no-arbitrage condition

$$
g_{v}=r-\pi / v .
$$

Finally, free-entry into R\&D requires

$$
w=v \epsilon n^{\phi} \quad \text { and } \quad u_{I}>0,
$$

in an equilibrium with innovation, or

$$
w>v \epsilon n^{\phi} \quad \text { and } \quad u_{I}=0 .
$$

Let $\chi \equiv C / K$ denote the ratio of consumption to physical capital, and $\psi \equiv H / n^{1-\phi}$, the knowledge-ideas ratio. Physical capital and claims to innovative firms are the assets in the 
economy. Aggregate wealth is then $A=K+n v$. From (3), (8)-(12) and (14) we can get the economy resource constraint, $\dot{K}=(1-\alpha \eta) Y-C$, which can be expressed as

$$
g_{K}=\frac{1-\alpha \eta}{\beta} r-\chi
$$

Using (4) and (17), we get

$$
g_{\chi}=\left(\frac{1}{\theta}-\frac{1-\alpha \eta}{\beta}\right) r+\chi-\frac{\rho}{\theta} .
$$

Some equations will be needed for solving the model. Log-differentiating the expressions for $r$ in (8), $w$ in (9), and $Y$ in (13), and eliminating $g_{Y}$, we get

$$
\begin{gathered}
g_{r}=-\frac{1-\beta-\eta}{\beta} g_{w}+\frac{(1-\alpha) \eta}{\alpha \beta} g_{n}, \\
g_{u_{P}}=-\frac{1-\eta}{\beta} g_{w}+\frac{(1-\alpha) \eta}{\alpha \beta} g_{n}+g_{K}-g_{H} .
\end{gathered}
$$

Log-differentiating (11) yields

$$
g_{g_{n}}=\left(g_{u_{I}}+g_{H}\right)-(1-\phi) g_{n} .
$$

\section{Equilibrium dynamics}

This section presents the dynamic systems that lead the different phases that an evolving economy can pass through. This is synthesis of the dynamics of AFS and Sequeira (2011) models, for sake of completeness.

\subsection{The neoclassical growth model}

The dynamics of the neoclassical growth model $\left(u_{E}=u_{I}=0\right)$ in terms of the variables $r$ and $\chi$ is given by

$$
\begin{aligned}
& g_{r}=-\frac{(1-\beta-\eta)(1-\alpha \eta)}{\beta(1-\eta)} r+\frac{1-\beta-\eta}{1-\eta} \chi, \\
& g_{\chi}=\left(\frac{1}{\theta}-\frac{1-\alpha \eta}{\beta}\right) r+\chi-\frac{\rho}{\theta} .
\end{aligned}
$$

Here, (22) results from (19) and (20), using (17) and that $g_{u_{P}}=g_{n}=g_{H}=0$.

\subsection{The knowledge economy}

The dynamics of the knowledge economy $\left(u_{E}=1-u_{P}>0\right.$ and $\left.u_{I}=0\right)$ in terms of the variables $r, \chi$ and $u_{P}$ is described by the following system:

$$
g_{r}=-\frac{1-\beta-\eta}{\beta}(r-\xi),
$$




$$
\begin{aligned}
g_{\chi} & =\left(\frac{1}{\theta}-\frac{1-\alpha \eta}{\beta}\right) r+\chi-\frac{\rho}{\theta}, \\
g_{u_{P}} & =\frac{(1-\alpha) \eta}{\beta} r-\chi-\xi\left(1-u_{P}\right)+\frac{(1-\eta) \xi}{\beta} .
\end{aligned}
$$

Eqs. (24) and (26) result from (19) and (20), using (5) to substitute for $g_{w},(17)$ and (2) to substitute for $g_{K}$ and $g_{H}$, and using that $g_{n}=0$. This stage of the economy can result from the neoclassical economy. With output growth rate determined by physical capital, equation (9) determines that the wage is also growing creating the incentives to accumulate human capital. Also in the neoclassical stage $r$ is decreasing. Both effects contribute to make condition (5) active.

\subsection{The innovative economy}

The dynamics of the innovative economy $\left(u_{E}=0\right.$ and $\left.u_{I}=1-u_{P}>0\right)$ in terms of the variables $r, \chi, u_{P}$ and $\psi$ is determined by the following system:

$$
\begin{aligned}
g_{r}=-\frac{1-\beta-\eta}{\beta} r+\frac{(1-\alpha) \eta}{\beta} \delta u_{P} \psi+ & \frac{(1-\alpha) \eta-\alpha(1-\beta-\eta) \phi}{\alpha \beta} \delta\left(1-u_{P}\right) \psi, \\
g_{\chi}= & \left(\frac{1}{\theta}-\frac{1-\alpha \eta}{\beta}\right) r+\chi-\frac{\rho}{\theta}, \\
g_{u_{P}}= & \frac{(1-\alpha) \eta}{\beta}\left\{r-\frac{\beta}{\eta(1-\alpha)} \chi+\right. \\
& {\left.\left[\frac{(1-\eta) u_{P}}{(1-\beta-\eta)\left(1-u_{P}\right)}-\frac{(1-\eta) \phi}{(1-\alpha) \eta}+\frac{1}{\alpha}\right] \delta\left(1-u_{P}\right) \psi\right\}, }
\end{aligned}
$$

The former system is obtained as follows. Log-differentiating the free-entry condition (15), we have $g_{w}=g_{v}+\phi g_{n}$. Substituting $g_{v}$ from (14), $\pi$ from (12), $w$ from (9), and $v$ from (15), we get

$$
g_{w}=r-\frac{(1-\alpha) \eta}{(1-\beta-\eta) u_{I}} u_{P} g_{n}+\phi g_{n}
$$

Now, Eqs. (27) and (29) result from (19) and (20), using (31) to substitute for $g_{w}$, (17) and (11) to substitute for $g_{K}$ and $g_{n}$, and taking into account that $g_{H}=0, u_{I}=1-u_{P}$, $g_{u_{I}}=-g_{u_{P}} u_{P} /\left(1-u_{P}\right)$ and $g_{n}=\delta\left(1-u_{P}\right) \psi$. Eq. (30) results from $g_{\psi}=-(1-\phi) g_{n}$. For this stage to follow the neoclassical stage, the initial value for the wage should be sufficient low to do not incentive the accumulation of human capital. A sufficiently high interest rate may also contribute to make the condition (6) to hold. Additionally, from the output growth rate due to physical capital that occurred during the neoclassical economy, a market for innovations is being created inducing the rising profits (from (12), without innovations, profits increases with output growth), which allows for the activation of the free entry condition (15). 


\subsection{The fully industrialized economy}

The dynamics of the fully industrialized economy $\left(u_{E}>0\right.$ and $\left.u_{I}>0\right)$ in terms of the variables $r, \chi, u_{P}$ and $\psi$ is determined by

$$
\begin{aligned}
g_{r} & =\frac{1-\beta-\eta}{\beta}(\xi-r)+\frac{(1-\alpha) \eta}{\alpha \beta} g_{n} \\
g_{\chi} & =\left(\frac{1}{\theta}-\frac{1-\alpha \eta}{\beta}\right) r+\chi-\frac{\rho}{\theta} \\
g_{u_{P}} & =\frac{(1-\alpha) \eta}{\beta}\left(r+\frac{g_{n}}{\alpha}\right)-\chi-\xi\left(1-u_{P}-\frac{g_{n}}{\delta \psi}\right)+\frac{(1-\eta)}{\beta} \xi \\
g_{\psi} & =\xi\left(1-u_{P}-\frac{g_{n}}{\delta \psi}\right)-(1-\phi) g_{n} .
\end{aligned}
$$

We have used that $u_{E}=1-u_{P}-u_{I}$ and $u_{I}=g_{n} /(\delta \psi)$. In the former system, $g_{n}$ should be substituted with

$$
g_{n}=\frac{1}{\phi}\left[\frac{(1-\alpha) \eta \delta u_{P} \psi}{1-\beta-\eta}-\xi\right],
$$

which results from (31) and (5), using (11). Eq. (32) is obtained from (19) and (5). Eq. (33) results from (4) and (17). From Eqs. (20) and (5), using (17) and (2), we get (34). From $g_{\psi}=g_{H}+(\phi-1) g_{n}$, using (2), we obtain (35).

The steady state of the fully-industrialized economy is described by the following proposition, which has been proved by Gómez (2011a).

Proposition 1 Let $\xi>\rho$. The economy has a unique positive steady-state equilibrium with positive long-run growth, in which the interest rate is

$$
\hat{r}=\frac{(1+M) \theta \xi-\rho}{(1+M) \theta-1}
$$

the ratio of consumption to physical capital is

$$
\hat{\chi}=\left(\frac{1-\alpha \eta}{\beta}-\frac{1}{\theta}\right) \hat{r}+\frac{\rho}{\theta}
$$

the long-run growth rate of intermediates is

$$
\hat{g}_{n}=\frac{M(\xi-\rho)}{(1-\phi)[(1+M) \theta-1]},
$$

the long-run growth rate of human capital is

$$
\hat{g}_{H}=(1-\phi) \hat{g}_{n},
$$

the share of labor devoted to production and R\&D can be obtained from

$$
\begin{gathered}
\hat{u}_{I}=\frac{(1-\alpha) \eta \hat{g}_{n}}{(1-\beta-\eta)\left(\xi-\hat{g}_{H}+\hat{g}_{n}\right)+(1-\alpha) \eta \hat{g}_{n}}\left(1-\frac{\hat{g}_{H}}{\xi}\right), \\
\hat{u}_{P}=1-\hat{u}_{I}-\frac{\hat{g}_{H}}{\xi}
\end{gathered}
$$


the knowledge-ideas ratio is

$$
\hat{\psi}=\hat{g}_{n} /\left(\delta \hat{u}_{I}\right),
$$

and the long-run growth rate of income, consumption, and physical capital is

$$
\hat{g}_{Y}=\hat{g}_{C}=\hat{g}_{K}=(1+1 / M) \hat{g}_{H},
$$

where $M=\alpha(1-\beta-\eta)(1-\phi) /[(1-\alpha) \eta]$, if and only if

$$
\theta>\frac{1+M(1-\rho / \xi)}{1+M} .
$$

The stability properties of the steady state have been analyzed by Gómez and Sequeira (2012) (see also Gómez, 2011a).

The fully industrialized economy can evolve from the knowledge economy or from the innovative economy. From the first, the knowledge economy creates the incentives to begin R\&D. In fact, accumulation of human capital determine that wages are growing less than in the neoclassical stage. Additionally, the continuing growing output is increasing profits that eventually lead to make $R \& D$ profitable, activating (15). From the second, the innovative economy would raise demand from human capital and consequently the wage (combine (13) with (9) to see this effect). This would contribute to making human capital accumulation a worth investment and this would eventually imply the verification of (5).

\section{Quantitative results}

This section presents the contribution of this article, providing different historically consistent sequences of economic trajectories driven solely by different initial factor endowments. The section begins by presenting the calibration of the model and then presents the simulation exercises.

\subsection{Calibration}

Our main aim is to find plausible transition paths for the economies after the Industrial Revolution. Thus the fitness of the model should be mainly evaluated according to its adherence to historical evidence. We calibrated the model using a mix of historical and current evidence. The share of physical capital $\beta$ has thought to have decreased since the industrial revolution. For example, Allen (2009) showed that this share oscillated between 0.6 and 0.4 between 1760 and 1913. Current data also points out for a share around 0.4 (e.g. Nehru and Dhareshwar (1993)). Thus, we have set an intermediate value of $\beta=0.5$. For the markup, $1 / \alpha$, we set the average value of the markup values in Norrbin (1993), which yield $\alpha=0.83$. Using $\beta, \alpha$, and the effect of R\&D in TFP growth from Coe and Helpman (1995) (0.234) together with the expression for this effect in the model steadystate, $(1-\alpha) \eta /[\alpha(1-\beta-\eta)]$, we obtain $\eta=0.267$. For the R\&D parameters, we set $\delta=0.1$ as is common in previous literature (e.g. Funke and Strulik (2000), Gómez (2005), Iacopetta (2010) and Reis and Sequeira (2007)) and for the spillover in R\&D we set $\phi=0.457$ as in Jones and Williams (2000). A value in this range is argued to be appropriate for a model 
with human capital accumulation, according to recent empirical evidence (see Reis and Sequeira (2007) and the empirical reference del Barrio-Castro et al. (2002)). For the utility parameters, we choose $\rho=0.02$ and $\theta=2$, values that are common in the literature (e.g. Funke and Strulik (2000), Gómez (2005), Iacopetta (2010) and Reis and Sequeira (2007)). We set a value for $\xi$ such that the steady-state growth rate replicates a plausible nowadays economic growth rate of $1.66 \% .^{1}$ Values in this order of magnitude are frequently used in numerical calibration exercises, so that our results can be compared to other findings.

One important test to the calibration is the comparison between the predicted steadystate values for some important macroeconomic variables with the current values for those variables. The steady-state shares of time devoted to work (70\%), to education (25\%) and to innovation (5\%), as well as the interest rate (5\%), the consumption to output ratio (62\%), and TFP growth $(0.5 \%)$ have quite plausible values, when compared with current values, e.g., for the US economy. In fact, our results entail that approximately one fourth of nonleisure time is devoted to human capital accumulation, and the other three fourths to work, which broadly accords with an average of 14 years spent on education and 35 years in work (e.g., Angelopoulos et al. (2008)). The average real interest rate from the World Bank (19872006 ) is $4.96 \% .^{2}$ TFP growth rate in the model steady-state is exactly the same as the data value between 1987 and 1995 (Bureau of Labor Statistics). ${ }^{3}$ For the consumption to output ratio, the average between 1987 and 2005 is 67\% (Bureau of Economic Analysis). ${ }^{4}$ This confirms that our calibration values are plausible in the sense that they allow to replicate some important macroeconomic variables values in recent periods of a developed country. The analysis of the next section would make possible to evaluate if, additionally, the model is capable of mimic long-term historical evolution.

\subsection{Simulation}

\subsubsection{Baseline Calibration}

This section presents some simulation results to show that the endogenous growth model with physical capital, human capital and R\&D (as in Sequeira (2011)) is indeed able to replicate a situation in which two identical economies, aside from their initial endowments, follow different sequences of the phases of development: one in which education precedes innovation and one in which innovation takes place before knowledge formation, being able to mimic the innovation and education dynamics for the first and for the second industrial revolutions.

Figures 1 and 2 depict two possible trajectories computed by backward integration (Brunner and Strulik, 2002), which aim is to describe the evolution of a simulated industrialized economy. As it can be observed, both economies display different sequences of development phases: one in which human capital accumulation precedes R\&D (Figure 1) and other in which innovation precedes knowledge accumulation (Figure 2). The unique difference between both economies are the initial values of the predetermined variables. If, for illus-

\footnotetext{
${ }^{1}$ This is the US growth rate for the period 1980 to 2009, from the Penn World Tables 7.0.

${ }^{2}$ http://data.worldbank.org/indicator/FR.INR.RINR?page $=1$

${ }^{3}$ From the 1987-2010 Major Sector Multifactor Productivity, http://www.bls.gov/mfp/mprdload.htm.

${ }^{4}$ From http://www.bea.gov//national/nipaweb/DownSS2.asp
} 

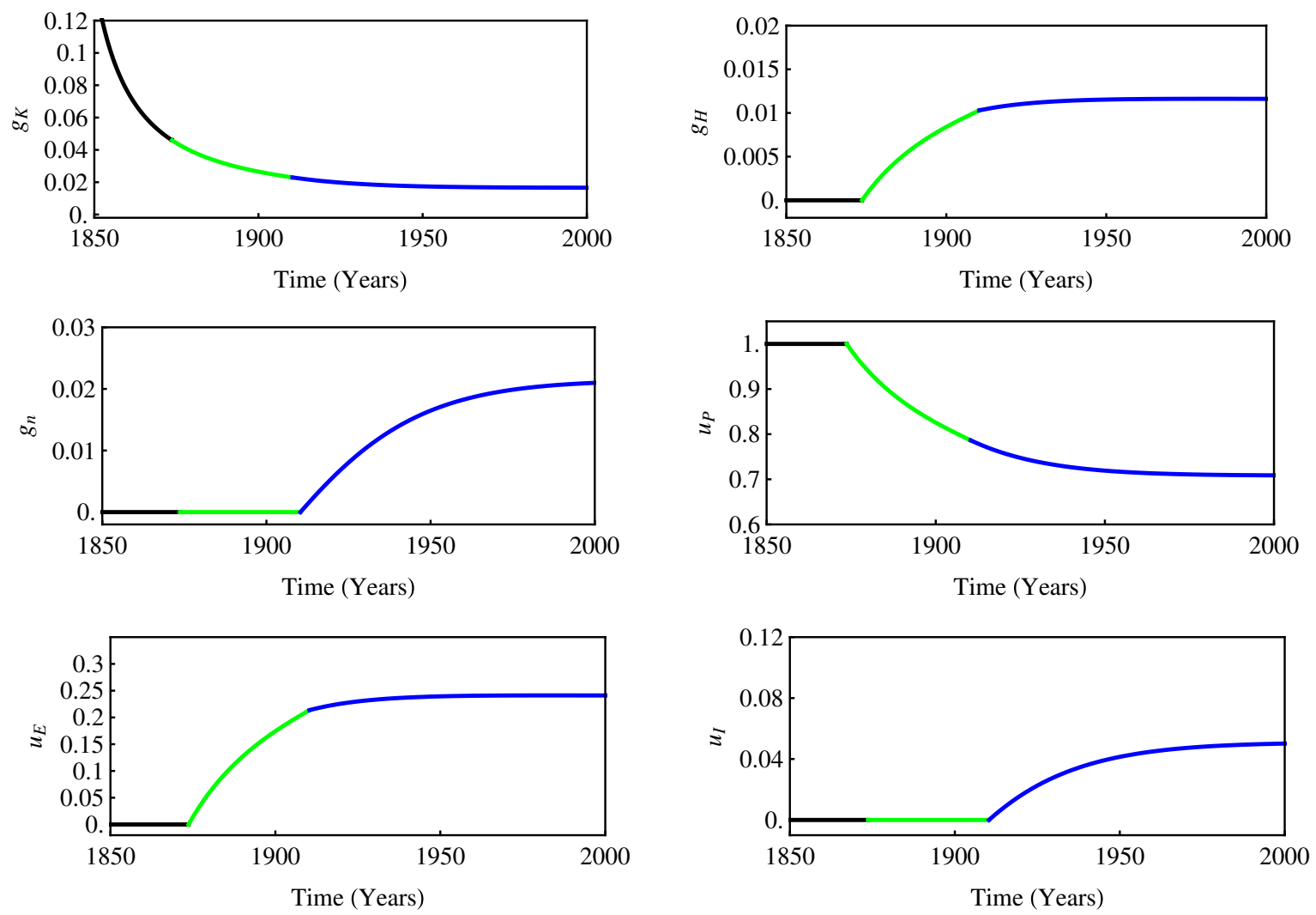

Figure 1: Time paths for representative variables: Education-innovation transition. Note: The simulation is extended backward to include an education phase without innovation, $u_{I}=0$, and then a neoclassical growth phase without education and innovation, $u_{E}=u_{I}=0$. The black line corresponds to the neoclassical growth phase, the green line to the education phase, and the blue line to the fully industrialized phase.

trative purposes, we normalize $n(0)=1,{ }^{5}$ the ratio of physical to human capital would be $K(0) / H(0)=3.18$ in the education-innovation case depicted in Figure 1 . The corresponding figure in the innovation-education case displayed in Figure 2 is $K(0) / H(0)=21.38$. Hence, Figures 1 and 2 illustrate the transitional dynamics of two economies with the same underlying technology and preference parameters that differ uniquely on factor endowments. It can be noted that the economy that follows an education-innovation sequence of development phases (Figure 1) has a lower physical to human capital ratio than the economy that follows an innovation-education sequence (Figure 2). This corresponds to the historical belief that human capital is relatively less important than physical capital in the first industrial revolution. ${ }^{6}$

\footnotetext{
${ }^{5}$ This means that initially, both economies have an equal initial number of technologies. Alternatively, other stock could be normalized and calculating the remaining two would be possible.

${ }^{6}$ In fact, not only education did not serve the industrial or technical purposes in nineteenth century Britain, as also this country has physical capital endowments that the followers did not, such as coal and resources from colonies (see e.g. (Mokyr, 2003) that pointed out Switzerland, New England - without coal and Belgium and Germany - without early colonies).
} 

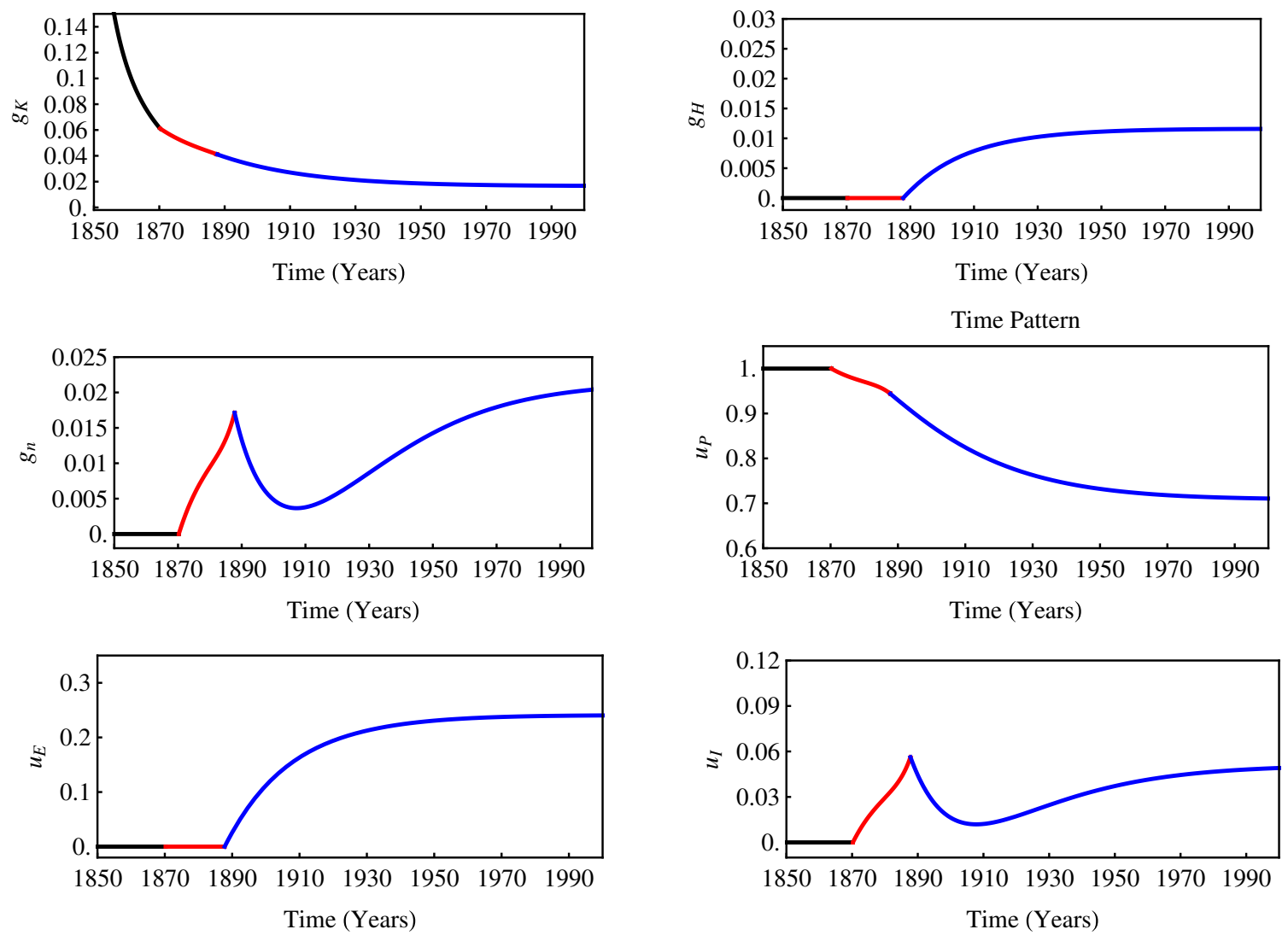

Figure 2: Time paths for representative variables: Innovation-education transition. Note: The simulation is extended backward to include an innovation phase without education, $u_{E}=0$, and then a neoclassical growth phase without education and innovation, $u_{E}=u_{I}=$ 0 . The black line corresponds to the neoclassical growth phase, the red line to the innovation phase, and the blue line to the fully industrialized phase.

Figure 1 depicts the dynamics of an economy that enters into the fully industrialized stage coming from a knowledge stage with no innovation, so that education precedes innovation. The economy starts in a neoclassical-growth phase with only physical capital accumulation. As the economy evolves, with a decreasing interest rate and an increasing wage, eventually, the economy enters the Uzawa-Lucas stage, with human capital accumulation and no R\&D activity. Thereafter, education time increases steadily and ultimately, due to the successive increase in the market for new products and wage moderation due to increasing supply of human capital, the economy enters the fully industrialized stage, in which innovation takes place as well. According with the evidence provided by Becker et al. (2011), this sequence of phases of economic development could reflect the prominent role that basic education may have played on the adoption of new technologies and, therefore, in the industrial catch-up of some technological follower nations. The implied transition dynamics in Figure 1 exhibits some realistic features, as the increasing pace of time devoted to R\&D (see, e.g., Jones, 1995, 2002). Time devoted to education increases rapidly at the onset, and then remains roughly constant. 
Figure 2 displays a sequence of growth stages in which innovation precedes human capital accumulation. The economy starts in a neoclassical-growth phase without knowledge formation and innovation. Eventually, the economy enters the innovative stage, with no human capital accumulation. This should happen due to a sufficiently low wage that do not incentive human capital accumulation but incentive industrialization due to low labor costs, a sufficiently high interest rate and an increasing market for industrial products due to economic growth. Thereafter, innovation time increases steadily and, ultimately, the economy enters the fully industrialized stage, with knowledge accumulation as well. In fact, the innovation process increases the demand for human capital and its wage which in some period in time, make human capital accumulation worth. This transition could be in accordance with historical evidence examined by Galor (2005) and Galor and Moav (2006) showing that in the first phase of industrialization, human capital played a limited role in the production process. In the second phase of industrialization, however, the increasing pace of technological progress ultimately brought about an industrial demand for human capital that stimulated human capital formation. The implied transition paths in Figure 2 shows that education time increases steadily according with data. The behaviour of innovation time, which increases sharply in the middle of the 19th century, decreases sharply after the onset of education and then increases rapidly, is more complex. In the model, the decrease in R\&D activity is associated with the need to allocate initial human capital to the education process. In the data, a broadly similar pattern can be observed in the evolution of U.S. patents per-capita issued and trademarks registered in the last two centuries displayed in Jovanovic and Rousseau (2005, Figure 12). As they argue, this behaviour reflects that patenting activity was more intense during the electrification technological revolution, at the beginning of the 19th century, and during the information technology revolution, after the second half of the 20th century. The sharp increase of the share of labor devoted to R\&D in the most recent period also accords with Jones (2002) data.

Figures 1 and 2 show that a large part of the aggregate behavior is qualitatively identical across different types of transition. The main difference between them is in the allocation of time to different activities and, specially, in time devoted to innovation, which follows a somewhat different pattern in the education-innovation case depicted in Figure 1 than in the innovation-education case displayed in Figure 2.

We mentioned that the specific sequence the economy would follow would depend on activating earlier or later the arbitrage and free-entry conditions (15) and (5). We have also mentioned that the innovation-education sequence would occur with low and moderately rising wages together with larger market for innovations while the education-innovation sequence would prevail with higher growth rate of wages with eventually smaller markets or previous growth rates. Recovering our comparison with the different trajectories with the first and the second industrial revolution, these reasoning would entail that we should expect to observe relatively lower and more constant wages in the first industrial revolution in England than in the second industrial revolution in the followers. Figure 10 in Galor (2005) seem to be consistent with the fact that before and in the beginning of the first industrial revolution there is a relative constant wage rate and most interesting, the wages of the craftsmen were substantially lower that wages in agriculture, while in France, exactly on the beginning of the second industrial revolution wages are rising steeply. Figure 3 in Galor (2005) also show a substantial output growth before the English industrial revolution. 
This and the large empire constituted the market that we can associate with some of the conditions for the innovation-education sequence to have occurred.

Therefore, our simulation results show that the model can generate a plausible educationinnovation development sequence in which human capital accumulation precedes R\&D (Figure 1) or an innovation-education sequence in which innovation precedes knowledge accumulation (Figure 2) depending uniquely on the initial endowments of the economy. Furthermore these simulation results entails a significant number of historically consistent features.

\subsubsection{Sensitivity Analysis}

In this section, we present a different simulation with the objective of testing the robustness of our result, according to which initial endowments are sufficient to determine if the economy follows an education-innovation or an innovation-education sequence of development, without the need to resorting also to parameter differences, as in Iacopetta (2010). ${ }^{7}$

For the sake of comparison, we consider a parameterization similar to Case 2 in Iacopetta (2010, Table 2) $(\beta=0.65 ; \alpha=0.62 ; \eta=0.2 ; \delta=0.1 ; \rho=0.023 ; \theta=2)$ to which we add the spillover value used above $(\phi=0.457)$. This is Iacopetta's preferred calibration as it is argued to yield the most realistic transition dynamics in his paper. ${ }^{8}$ Figures 3 and 4 show that different sequences of development could also be obtained in this case depending only on the initial endowments. Interestingly, most of the historical features displayed in Figures 3 and 4 are common to our baseline simulation, with slight differences, and most of them remain realistic historical features. Similar results have been obtained for different calibrations.

When comparing these results with those previously reported by Iacopetta (2010) and Gómez (2011b), we can conclude that our model is superior in replicating empirically reasonable trajectories in both the innovation-education sequence and in the education-innovation sequence, and only resorting to different endowments as an explanation. In fact, the simulation results for this case reported in Iacopetta (2010) are flawed because the steady state is unstable (see Gómez, 2011b, Table 1). Gómez (2011b, Figure 2), in a model with duplication externalities but with no R\&D spillovers, shows a realistic innovation-education sequence. However, in this model the condition for no time devoted to innovation, $w H_{n}>v \epsilon H_{n}^{\lambda} n^{\phi}$, cannot be satisfied if $\lambda<1$, so that the model with duplication externalities cannot generate an education-innovation sequence.

In summary, the result that differences in initial endowments alone may determine whether the economy follows an innovation-education sequence or an education-innovation sequence seems to be robust to different parameterizations. This is relevant as it affects the view according to which differences in structural parameters and policies, that can be

\footnotetext{
${ }^{7}$ Iacopetta (2010) is not explicit about differences in initial conditions. As shown by Gómez (2005), the AFS model considered by Iacopetta (2010) features two state-like variables, $r$ and $\psi=H / n$. Given that their initial values are not kept constant across simulations, there are differences in initial conditions. Thus, for example, the initial value of $\psi=H / n$ in Case 1 (Iacopetta, 2010, Figure 2) is 0.949, its initial value in Case 2 (Iacopetta, 2010, Figure 3) is 1.04, its initial value in Case 3 (Iacopetta, 2010, Figure 4) is 1.248, and its initial value in Case 4 (Iacopetta, 2010, Figure 5) is 0.183.

${ }^{8}$ We should stress that these calibration values are less realistic than our baseline parameters set in two main aspects: it assumes a particulary high share of physical capital in production $(\beta)$ and it assumes an unrealistic high markup $(1 / \alpha)$.
} 

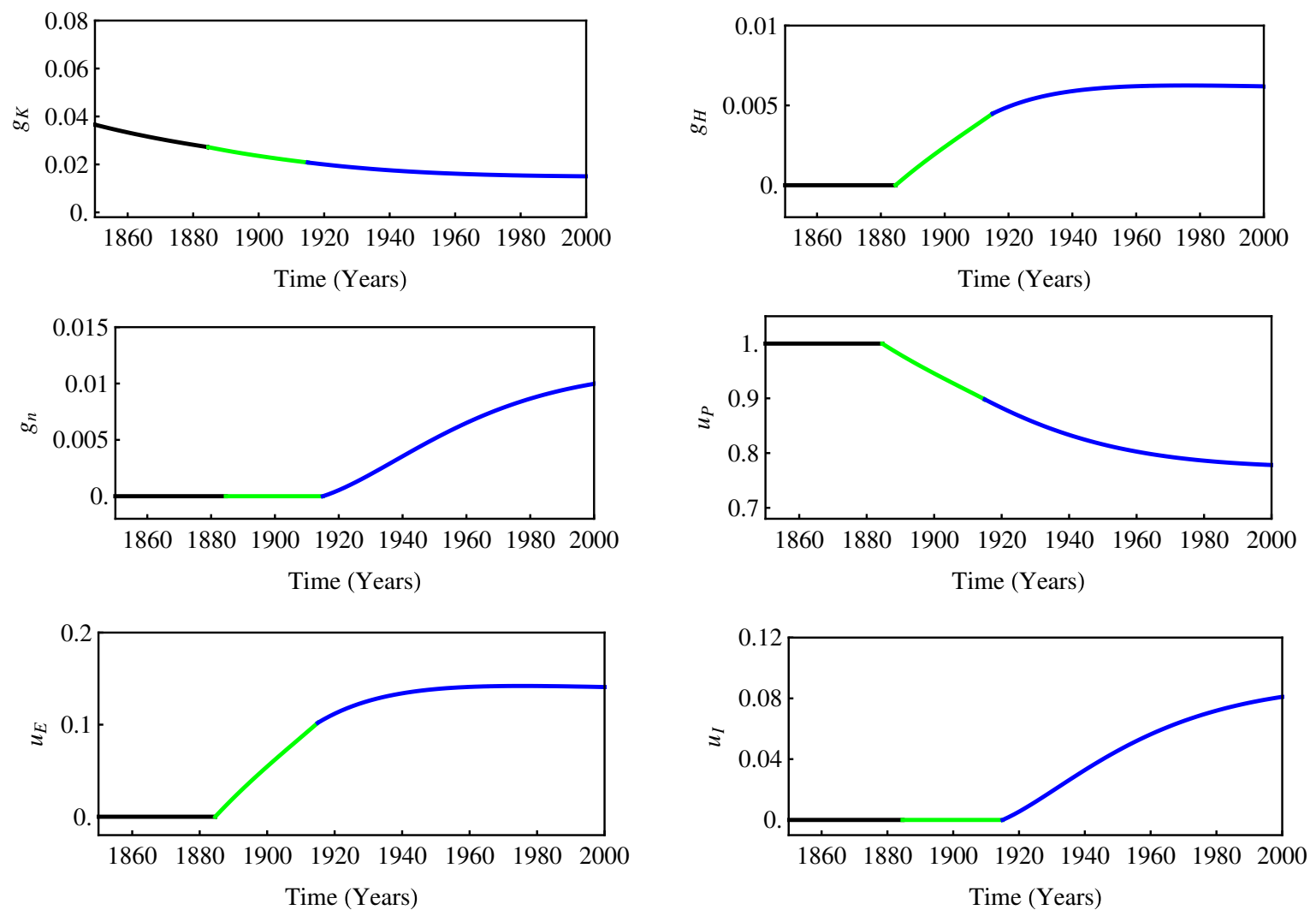

Figure 3: Time paths for representative variables: Education-innovation transition. Note: The simulation is extended backward to include an education phase without innovation, $u_{I}=0$, and then a neoclassical growth phase without education and innovation, $u_{E}=u_{I}=0$. The black line corresponds to the neoclassical growth phase, the green line to the education phase, and the blue line to the fully industrialized phase.

changed at any historical time, are crucial to determine the path of development. On the contrary, this article illustrates the view according to which initial endowments alone can determine the sequence of development stages, giving a determinant role to geography and endowments, which cannot be easily changed. Hence, parameter differences would not be needed to explain different sequences of stages of development.

\section{Conclusion}

This paper shows that a model of endogenous growth with physical capital, human capital and R\&D — with spillovers in R\&D - can replicate a situation in which two identical economies, aside from their initial factor endowments, follow different sequences of development phases; i.e., an innovation-education sequence or an education-innovation sequence. Alternatively said, initial factor endowments alone determine whether innovation precedes education or vice versa in the industrializing process followed by an evolving economy. This means that differences in preference, production and/or policy parameters are not required 

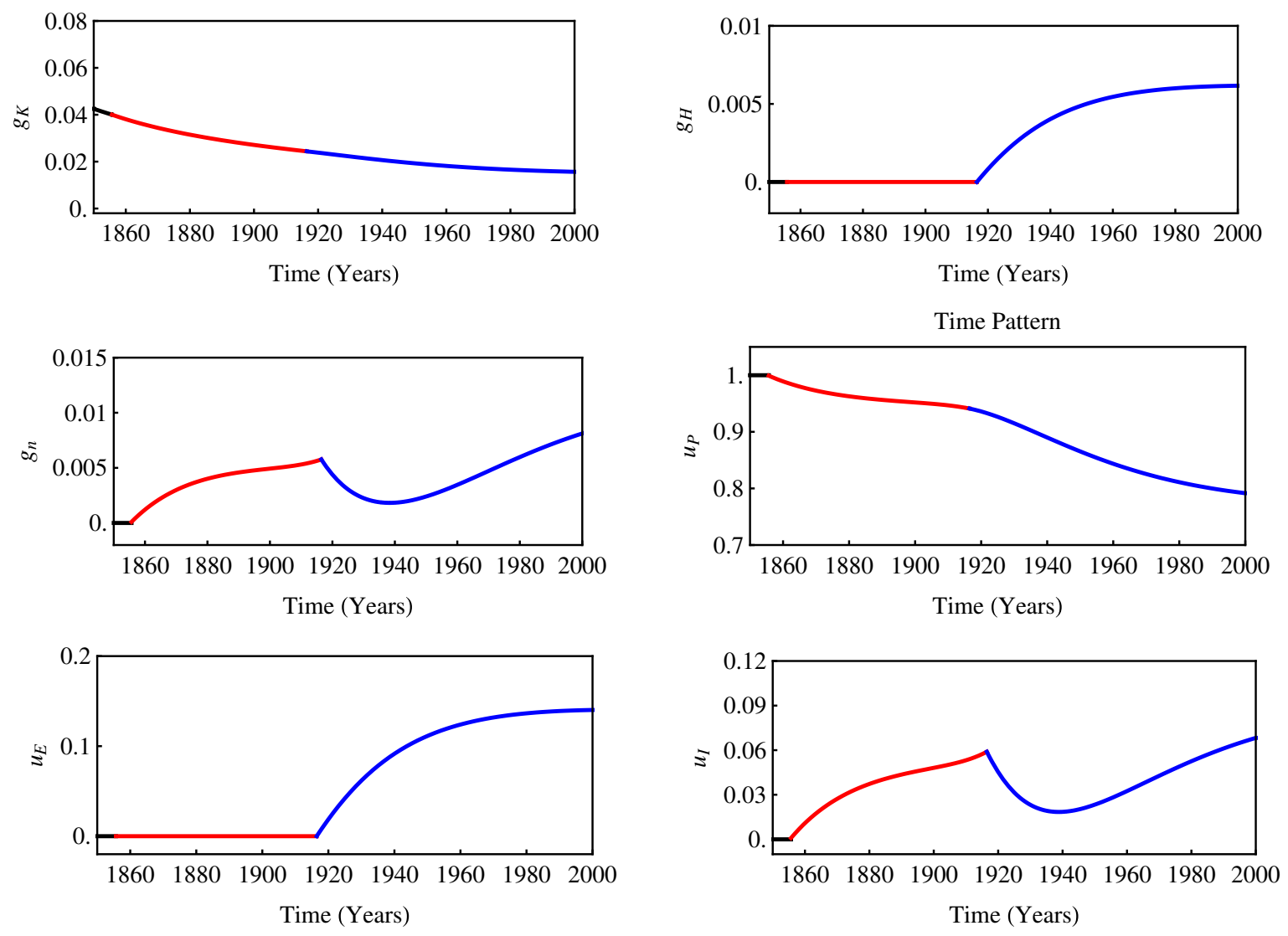

Figure 4: Time paths for representative variables: Innovation-education transition. Note: The simulation is extended backward to include an innovation phase without education, $u_{E}=0$, and then a neoclassical growth phase without education and innovation, $u_{E}=u_{I}=$ 0 . The black line corresponds to the neoclassical growth phase, the red line to the innovation phase, and the blue line to the fully industrialized phase.

to explain different sequences of economic development. Thus, we uncover the great richness of the model, which can explain different industrializing experiences beginning on innovation or education only by differences in factor endowments. Moreover, the paper shows that both types of transitional dynamics mimics important historical features of economic evolution that followed the first - for the innovation-education sequence - and the second - for the education-innovation sequence - industrial revolutions.

\section{Acknowledgements}

Manuel Gómez gratefully acknowledges financial support from the Spanish Ministry of Science and Innovation through Grant ECO2011-25490. Tiago Sequeira gratefully acknowledges financial support from the Portuguese Ministry of Science, Technology and Higher Education, through FCT project PTDC/EGE-ECO/102238/2008. 


\section{References}

Acemoglu, D., Johnson, S., and Robinson, J. (2001). The colonial origins of comparative development: An empirical investigation. American Economic Review, 91(5):1369-1401.

Allen, R. (2009). Engels pause: Technical change, capital accumulation, and inequality in the british industrial revolution. Explorations in Economic History, 46(4):418-435.

Angelopoulos, K., Malley, J., and Philippopoulos, A. (2008). Macroeconomic effects of public education expenditure. CESifo Economic Studies, 54(3):471-498.

Arnold, L. G. (2000). Endogenous growth with physical capital, human capital and product variety: A comment. European Economic Review, 44(8):1599-1605.

Becker, S. M., Hornung, E., and Woessmann, L. (2011). Education and catch-up in the Industrial Revolution. American Economic Journal: Macroeconomics, 3(3):92-126.

Brunner, M. and Strulik, H. (2002). Solution of perfect foresight saddlepoint problems: A simple method and applications. Journal of Economic Dynamics and Control, 26(5):737753.

Coe, D. and Helpman, E. (1995). International R\&D spillovers. European Economic Review, 39(5):859-887.

del Barrio-Castro, T., Lopez-Bazo, E., and Serrano-Domingo, G. (2002). New evidence on international R\&D spillovers, human capital and productivity in the OECD. Economics Letters, 77(1):41-45.

Easterly, W. and Levine, R. (2003). Tropics, germs, and crops: how endowments influence economic development. Journal of Monetary Economics, 50(1):3-39.

Funke, M. and Strulik, H. (2000). On endogenous growth with physical capital, human capital and product variety. European Economic Review, 44(3):491-515.

Galor, O. (2005). From stagnation to growth: Unified growth theory. In Aghion, P. and Durlauf, S., editors, Handbook of Economic Growth, volume 1, chapter 4, pages 171-293. Elsevier, Amsterdam.

Galor, O. (2010). The 2008 Lawrence R. Klein Lecture - Comparative economic development: Insights from unified growth theory. International Economic Review, 51(1):1-44.

Galor, O. and Moav, O. (2006). Das human-kapital: A theory of the demise of the class structure. Review of Economic Studies, 73(1):85-117.

Gómez, M. A. (2005). Transitional dynamics in an endogenous growth model with physical capital, human capital and R\&D. Studies in Nonlinear Dynamics 85 Econometrics, 9(1):Article 5.

Gómez, M. A. (2011a). Duplication externalities in an endogenous growth model with physical capital, human capital and R\&D. Economic Modelling, 28(1-2):181-187. 
Gómez, M. A. (2011b). Stages of economic development in an innovation-education growth model. Studies in Nonlinear Dynamics 83 Econometrics, 15(4):Article 6.

Gómez, M. A. and Sequeira, T. N. (2012). A note on R\&D spillovers in an endogenous growth model with physical capital, human capital and varieties. Macroeconomic Dynamics, 16(4):in press.

Iacopetta, M. (2010). Phases of economic development and the transitional dynamics of an innovation-education growth model. European Economic Review, 54(2):317-330.

Iacopetta, M. (2011). Formal education and public knowledge. Journal of Economic Dynamics and Control, 35(5):676-693.

Jones, C. I. (1995). R\&D-based models of economic growth. Journal of Political Economy, 103(4):759-784.

Jones, C. I. (2002). Sources of U.S. economic growth in a world of ideas. American Economic Review, 92(1):220-239.

Jones, C. I. and Williams, J. C. (2000). Too much of a good thing? The economics of investment in R\&D. Journal of Economic Growth, 5(1):65-85.

Jovanovic, B. and Rousseau, P. L. (2005). General purpose technologies. In Aghion, P. and Durlauf, S., editors, Handbook of Economic Growth, volume 1, chapter 18, pages 1181-1224. Elsevier.

Mitch, D. (1993). The British Industrial Revolution: An economic perspective. In Mokyr, J., editor, The Role of Human Capital in the First Industrial Revolution, pages 267-307. Westview.

Mokyr, J. (1990). The Lever of Riches. Oxford University Press.

Mokyr, J. (2003). Why was the industrial revolution a european phenomenon? Supreme Court Economic Review, 10:27-63.

Nehru, V. and Dhareshwar, A. (1993). A new database on physical capital stock: sources, methodology and results. Revista de Analisis Economico, 8(1):37-59.

Norrbin, S. (1993). The relation between price and marginal cost in U.S. industry: A contradiction. Journal of Political Economy, 101(6):1149-1164.

Reis, A. B. and Sequeira, T. (2007). Human capital and overinvestment in R\&D. Scandinavian Journal of Economics, 109(3):573-591.

Sequeira, T. N. (2011). R\&D spillovers in an endogenous growth model with physical capital, human capital, and varieties. Macroeconomic Dynamics, 15(2):223-239. 